Published In: Proteomics 8, 893-908 (2008)

\title{
Recent advances in plant cell wall proteomics
}

Elisabeth JAMET, Cécile ALBENNE, Georges BOUDART, Muhammad IRSHAD, Hervé CANUT, Rafael PONT-LEZICA

UMR 5546 CNRS-Université Toulouse III, Pôle de Biotechnologie Végétale, 24 Chemin de Borde Rouge, BP 42617 Auzeville, 31326 Castanet-Tolosan, France

Running title: Plant cell wall proteomics

Corresponding author: Elisabeth Jamet

BP 42617, Auzeville

F-31326 - Castanet-Tolosan

Phone: $33+562193530$

FAX: 33+532193502

E-mail: jamet@scsv.ups-tlse.fr

Keywords: Arabidopsis thaliana, bioinformatics, cell wall, mass spectrometry, plant, proteomics

\begin{abstract}
Abbreviations: AG, arabinogalactan; AGP, arabinogalactan protein; CWMEI, cell wall modifying enzyme inhibitor; CWP, cell wall protein; DUF, domain of unknown function; GAP, glycosylphosphatidyl inositol-anchored protein; GH, glycoside hydrolase; GRP, Gly-rich protein; GT, glycosyl transferase; H/PRP, Hyp/Pro-rich protein; HRGP, Hyp-rich glycoprotein; LRR, leucine-rich repeat; LTP, lipid transfer protein; PG, polygalacturonase; PGIP, polygalacturonase inhibitor protein; PME, pectin methyl esterase; PMEI, pectin methyl esterase inhibitor; RLK, receptor lectin kinase; SBP, soybean peroxidase; XEGIP, xyloglucan endoglucanase inhibiting protein.
\end{abstract}




\begin{abstract}
The plant extracellular matrix contains typical polysaccharides such as cellulose, hemicelluloses and pectins that interact to form dense interwoven networks. Plant cell walls play crucial roles during development and constitute the first barrier of defense against invading pathogens. Cell wall proteomics has greatly contributed to the description of the protein content of a compartment specific to plants. Around 400 cell wall proteins (CWPs) of Arabidopsis representing about one fourth of its estimated cell wall proteome, have been described. The main points to note are that: (i) the diversity of enzymes acting on polysaccharides suggests a great plasticity of cell walls; (ii) CWPs such as proteases, polysaccharide hydrolytic enzymes, and lipases may contribute to the generation of signals; (iii) proteins of unknown functions were identified, suggesting new roles for cell walls. Recently, the characterization of PTMs such as $\mathrm{N}$ and $O$-glycosylations improved our knowledge of CWP structure. The presence of many glycoside hydrolases and proteases suggests a complex regulation of CWPs involving various types of post-translational events. The first 3D-structures to be resolved gave clues about the interactions between CWPs, or between CWPs and polysaccharides. Future work should include: extracting and identifying CWPs still recalcitrant to proteomics, describing the cell wall interactome, improving quantification, and unraveling the roles of each of the CWPs.
\end{abstract}

\title{
1 Introduction
}

Plant cell walls are composite structures, mostly made up of polysaccharides, proteins and lignins, the latter being found only in specific cell types. Polysaccharides represent up to $95 \%$ of cell wall mass whereas CWPs only account for 5 to $10 \%$ [1]. Models of cell wall structure describe the arrangement of their components into dense interwoven networks of polysaccharides and proteins $[2,3]$. Cellulose microfibrils and hemicelluloses constitute a network, another one is formed by structural proteins, e.g. extensins, both embedded in a pectin matrix. Plant cell walls are dynamic structures essential not only for cell division, enlargement, and differentiation, but also for response to environmental constraints $[4,5]$.

Cell wall dynamics is illustrated by immunodetection of various carbohydrate epitopes in developing roots of Arabidopsis thaliana. These epitopes are unevenly distributed among the walls of a given cell and their location around cells is regulated during development [6]. Such a control of the fine structure of cell walls may be performed by addition of new cell wall material and/or modification of existing components by cell wall enzymes. Many essential roles of such cell wall proteins (CWPs) during development or in response to environmental constraints will be illustrated in this review.

Three types of CWPs can be distinguished on the basis of their interactions with cell wall components [7]. Loosely bound CWPs have little or no interactions with cell wall polysaccharides and thus move freely in the intercellular space. Alternatively, CWPs can be weakly bound to the matrix by Van der Waals interactions, hydrogen bonds, hydrophobic or ionic interactions. Even though most of the cell wall polysaccharides are neutral, pectins contain polygalacturonic acid residues that provide negative charges for interactions with basic proteins. Such interactions could be modulated by $\mathrm{pH}$, degree of pectin esterification, $\mathrm{Ca}^{2+}$ concentration, 
as well as the mobility and diffusion coefficients of the pectins [3]. Finally, CWPs can be strongly bound to cell wall components and become resistant to salt-extraction. For instance, extensins are cross-linked by covalent links [8].

Despite the difficulties specific to the extraction and analysis of CWPs, cell wall proteomics has become an active field during the last years. Today, around $400 \mathrm{CWPs}$ have been described in Arabidopsis thanks to cell wall proteomic analyses. They represent about one fourth of expected cell wall proteins [7]. Results have mainly been obtained with the model plant Arabidopsis [9-23]. Some studies have also been performed on Medicago sativa [24], Zea mays [25], and Cicer arietinum [26]. The resulting cell wall proteomes were different showing in another way that cell wall structure and composition are regulated during development. They also allow comparison between cell wall proteomes of different organs in relation to their functions. The characterization of the $Z$. mays xylem sap proteome should be mentioned since it also reveals secreted proteins [27]. Finally, the plasma membrane proteome provides information on CWPs interacting with plasma membranes [28].

This review focuses on Arabidopsis cell wall proteomics with special emphasis on CWP structure and function. Strategies will be discussed based on specific properties of cell walls and CWPs. Beyond protein identification, questions concerning protein structures, e.g. posttranslational modifications (PTMs) and interactions with cell wall components, will be addressed. Finally, the main features emerging from cell wall proteomics will be highlighted, i.e. plasticity of cell walls, signaling via cell walls, and identification of many proteins with an as yet unknown function.

\section{Specific strategies for plant cell wall proteomics}

There are several constraints in performing cell wall proteomics: (i) the lack of a delimiting membrane may result in the loss of CWPs during the isolation procedure, (ii) polysaccharide networks of cellulose, hemicelluloses, and pectins form potential traps for intracellular proteins that contaminate CWP extracts, (iii) CWPs are embedded in a polysaccharide matrix and interact in different ways with other cell wall components, making the extraction of some of them challenging, (iv) separation of CWPs by 2-DE is not very efficient since most of them are basic glycoproteins, (v) identification of heavily $O$-glycosylated CWPs is very hard using peptide mass mapping by MS. Specific strategies have been developed to overcome these difficulties.

\subsection{Extraction methods}

For the reasons stated above, a complete cell wall proteome cannot be obtained with a single extraction procedure. Employing living cells is probably the best choice to avoid contamination with intracellular proteins [7, 29]. Fig. 1 shows three different non-destructive methods for CWP extraction. Both loosely- and weakly-bound CWPs can be released using these extraction methods. In certain cases, it is not possible to apply the above methods, and destructive ones should be employed [7, 29] (Fig. 1). The general practice is the purification of cell walls followed by extraction of the proteins with salts. However, this approach implies losing most of the loosely bound CWPs, and the contamination with intracellular proteins sticking non-specifically to the cell walls is considerably increased [16] 
Whatever the starting material, living cells or purified cell walls, the composition of the extraction buffer is critical and determines which type of proteins can be released from the cell walls. Most loosely bound CWPs are dissolved with a low ionic strength solution or simply with $0.3 \mathrm{M}$ mannitol infiltrated in living tissues such as leaves [13]. Weakly bound CWPs are

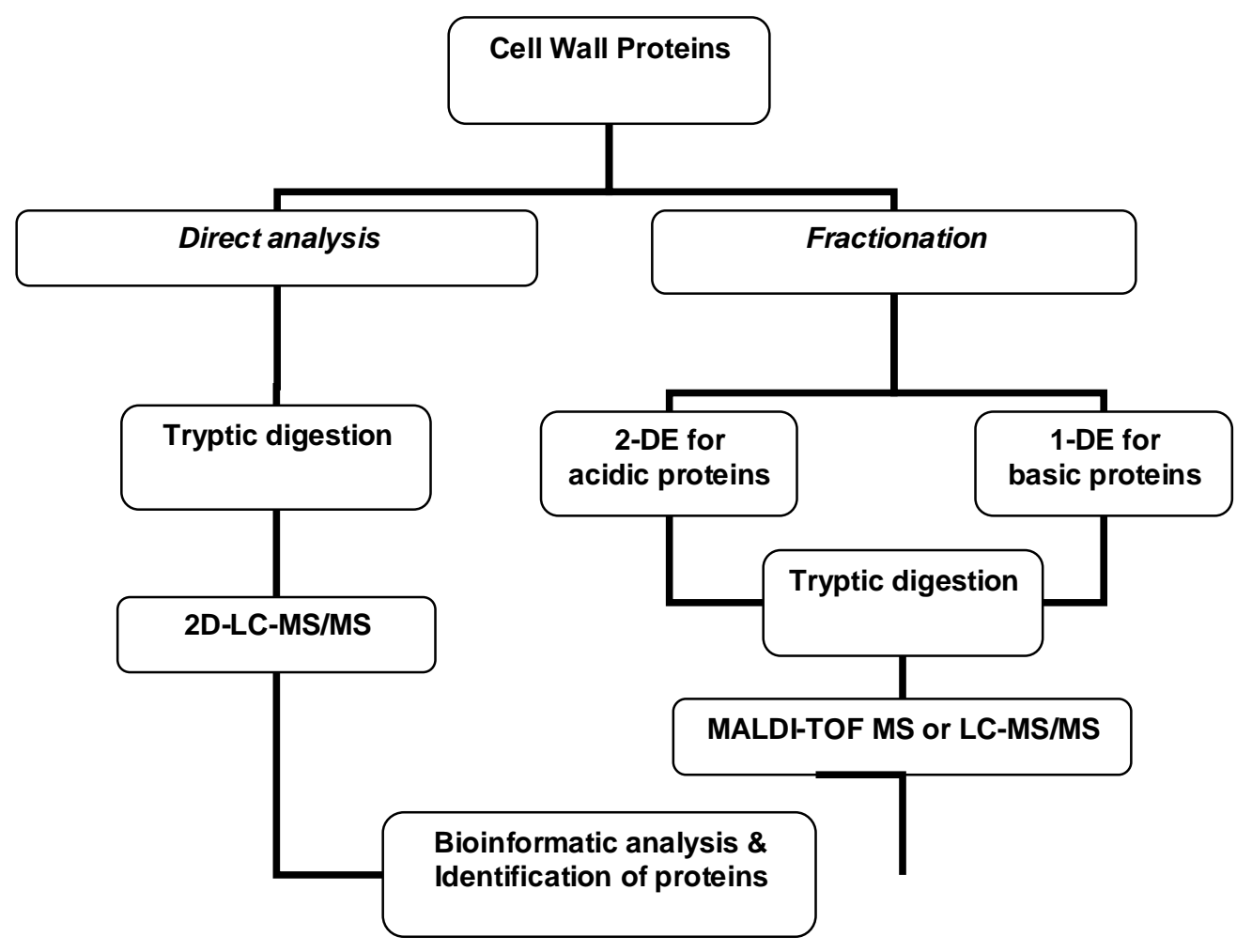

Figure 1. Strategies of CWP extraction for proteomics. Two kinds of procedure can be used for sample preparation prior to CWP extraction and analysis. Non-destructive methods consist of in analysis of proteins secreted in culture media $[11,14](\mathrm{A})$, washings of cells with salt solutions $[11,18](B)$ or vacuum infiltration of organs with salt solutions $[13,25](C)$. Destructive methods require grinding the plant material either to purify cell walls $[10,15,16]$ or to select CWPs using a specific property [22]. In all cases, either all CWPs can be considered for further analysis or a sub-proteome can be selected through a specific

extracted by salts such as $\mathrm{NaCl}, \mathrm{LiCl}$ or $\mathrm{CaCl}_{2}$. While $\mathrm{LiCl}$ was used to extract Hyp-rich glycoproteins (HRGPs) from the glycoprotein matrix of the green alga Chlamydomonas reinhardii [30], the most efficient salt for the extraction of higher plant CWPs is $\mathrm{CaCl}_{2}$ [13]. However, strongly-bound CWPs are still resistant to salt-extraction. An example is provided by peroxidases, lacking in the rosette proteome whereas peroxidase activities have been found in rosette leaves [13]. The use of several salt solutions to release CWPs by vacuum-infiltration was probably not efficient to elute peroxidases that can be bound to $\mathrm{Ca}^{2+}$ pectates [31]. Also, structural proteins are under-represented in all cell wall proteomes. Either they were not extracted from cell walls due to their covalent cross-linking in networks [8] or they were not identified using MS due to the absence of sites for tryptic digestion or to their high level of glycosylation 
(see below). A sequential treatment with enzymes able to degrade cell wall polysaccharides was proposed to extract strongly bound CWPs from Candida albicans [32]. However, such methods have not yet been applied to plant cell walls. Finally, the low abundance of many CWPs is certainly an important limiting factor for their identification.

\subsection{Purification and detection of specific CWPs}

Affinity chromatography is a widespread method to get sub-proteomes. Since CWPs go through the secretory pathway, most of them are supposed to be glycosylated. Affinity chromatography using lectins can select glycoproteins containing different carbohydrate moieties. Con A was used to select $N$-glycosylated proteins and 89 putative cell wall glycoproteins were identified from mature Arabidopsis stems [22].

A specific sub-proteome has been isolated by phase partitioning and sensitivity to phospholipase $\mathrm{C}$ from lipid rafts to analyze glycosylphosphatidyl inositol-anchored proteins (GAPs) that are located at the cell surface [12].

Arabinogalactan proteins (AGPs) are proteoglycans with $O$-glycosylation comprising up to $90 \%$ of the polysaccharides and specifically recognized by the $\beta$-Yariv reagent through an interaction of the antigen-antibody type [21]. AGPs are not revealed by classical gel staining by CBB but are revealed as a smear with the $\beta$-Yariv reagent (Fig. 2A). Another case is that of GRPs containing only a few aromatic amino acids, thus escaping the classical gel staining by CBB. An alternative staining method should be used such as amido black. As shown in Fig. 2B, GRPs are revealed after amido black staining as two additional bands at 22 and $20 \mathrm{kDa}$. On the contrary, the band at $38 \mathrm{kDa}$ containing a GRP is stained less by amido black staining than by CBB staining.

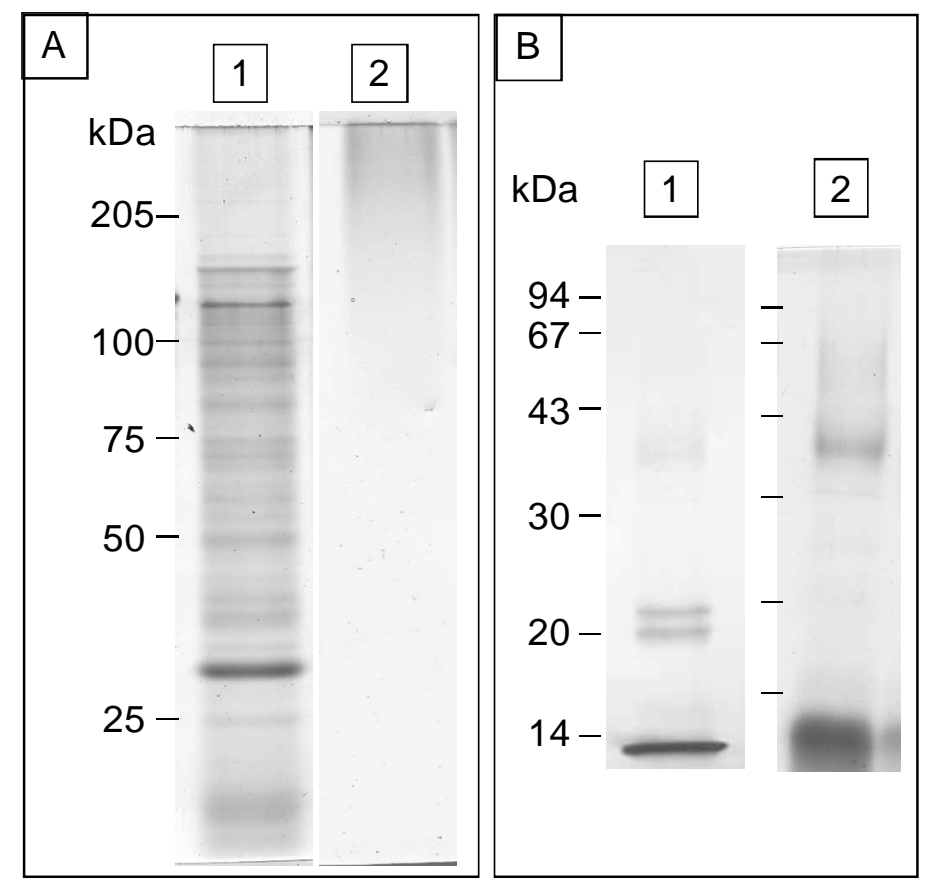

Figure 2. Staining of CWP with specific properties. Some CWPs behaving like proteoglycans or having biased amino acid composition do not stain with $\mathrm{CBB}$ and thus might escape proteomic analysis. A. Comparative staining of CWPs secreted by etiolated seedlings grown for 14 days in liquid culture medium with $\mathrm{CBB}(1)$ and $\beta$ Yariv reagent (2). Proteins were analyzed as previously described [14]. B. Comparative staining of a CWP protein fraction extracted from 11-dayold etiolated hypocotyls with amido black (1) and $\mathrm{CBB}$ (2). CWPs were extracted with $\mathrm{CaCl}_{2}$ and $\mathrm{LiCl}$ from purified cell walls [16] and subsequently separated by cationic exchange chromatography (Irshad et al. unpublished results). The analyzed fraction was eluted with $0.8 \mathrm{M} \mathrm{NaCl}$. 


\subsection{Analysis of CWPs}

The analysis of CWPs can be performed in different ways (Fig. 3). Multidimensional protein identification technology (MudPIT) is a powerful tool allowing the identification of a large number of proteins by direct tryptic digestion of the protein extract, followed by peptide sequencing through 2D-LC-MS/MS [10]. This direct analysis is primarily important for CWPs, which contain a great proportion of basic glycoproteins, poorly resolved by the classical 2-DE (Fig. 4). An alternative is the fractionation of CWPs by cation exchange chromatography followed by $2-\mathrm{DE}$ or $1-\mathrm{DE}$ for acidic or basic proteins respectively $[11,13]$. In-gel tryptic digestion is performed prior to peptide mass mapping using MALDI-TOF MS or peptide sequencing by LC-MS/MS. It should be noted that these strategies do not provide exactly the same results, but their combination can increase the coverage of a proteome [33].

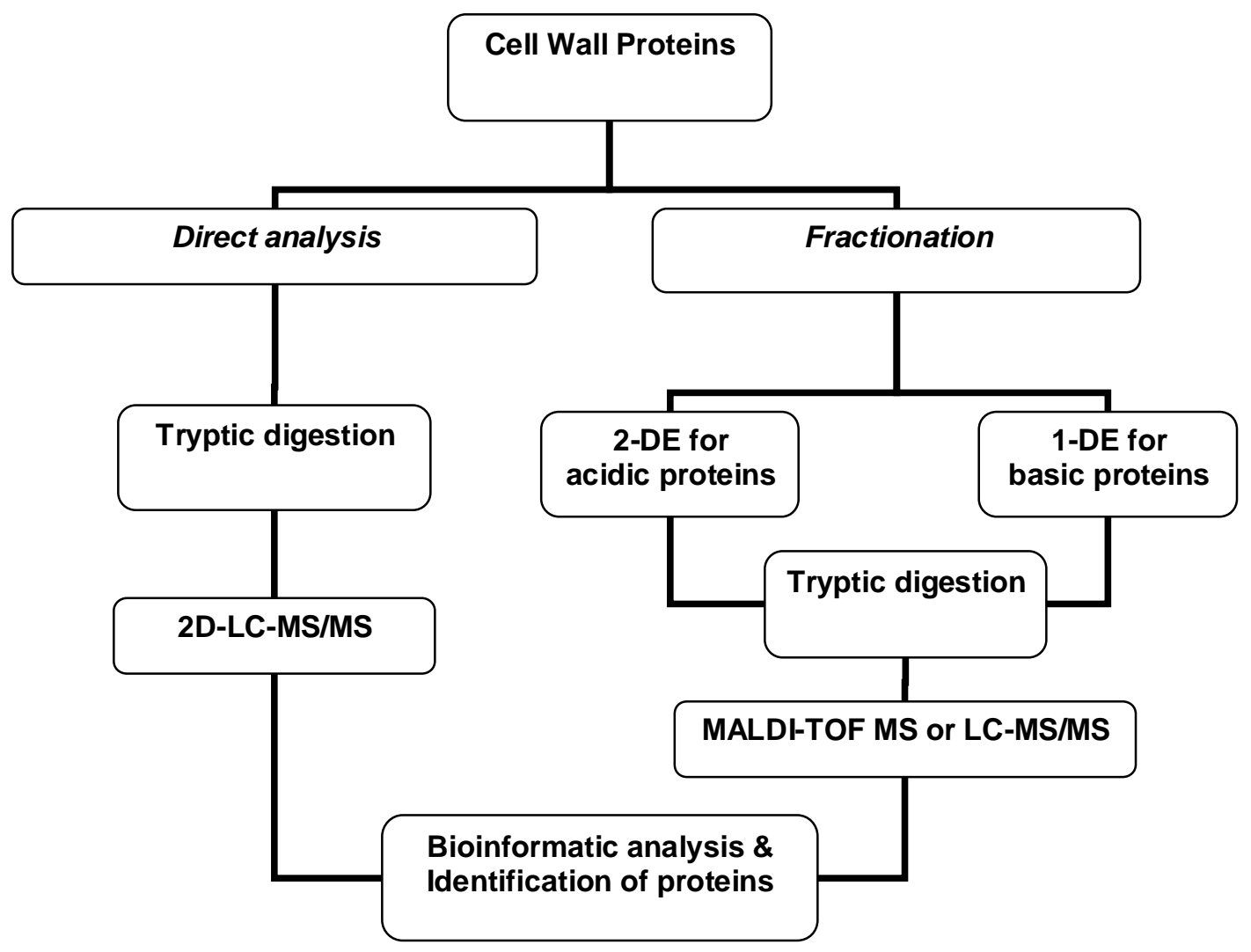

Figure 3. Strategies for CWP proteomic analyses. Once extracted, CWPs can be directly analyzed by 2D-LC-MS/MS after tryptic digestion. Alternatively, they can be fractionated according to their $\mathrm{pI}$ and subsequently separated by 2-DE or 1-DE prior to in-gel tryptic digestion and MALDI-TOF MS or LC-MS/MS analysis. In all cases, the last step of the procedure consists in a bioinformatic analysis to get final identification of the proteins.

Identification of heavily $O$-glycosylated CWPs requires a deglycosylation step prior to tryptic digestion and analysis by MS or Edman sequencing. The most efficient way to perform this deglycosylation without disruption of the peptide bonds is hydrogen fluoride (HF) treatment in 
anhydrous conditions [34]. It has been successfully performed with AGPs [21], Hyp-rich/Pro-rich proteins (H/PRPs) and extensins [35].

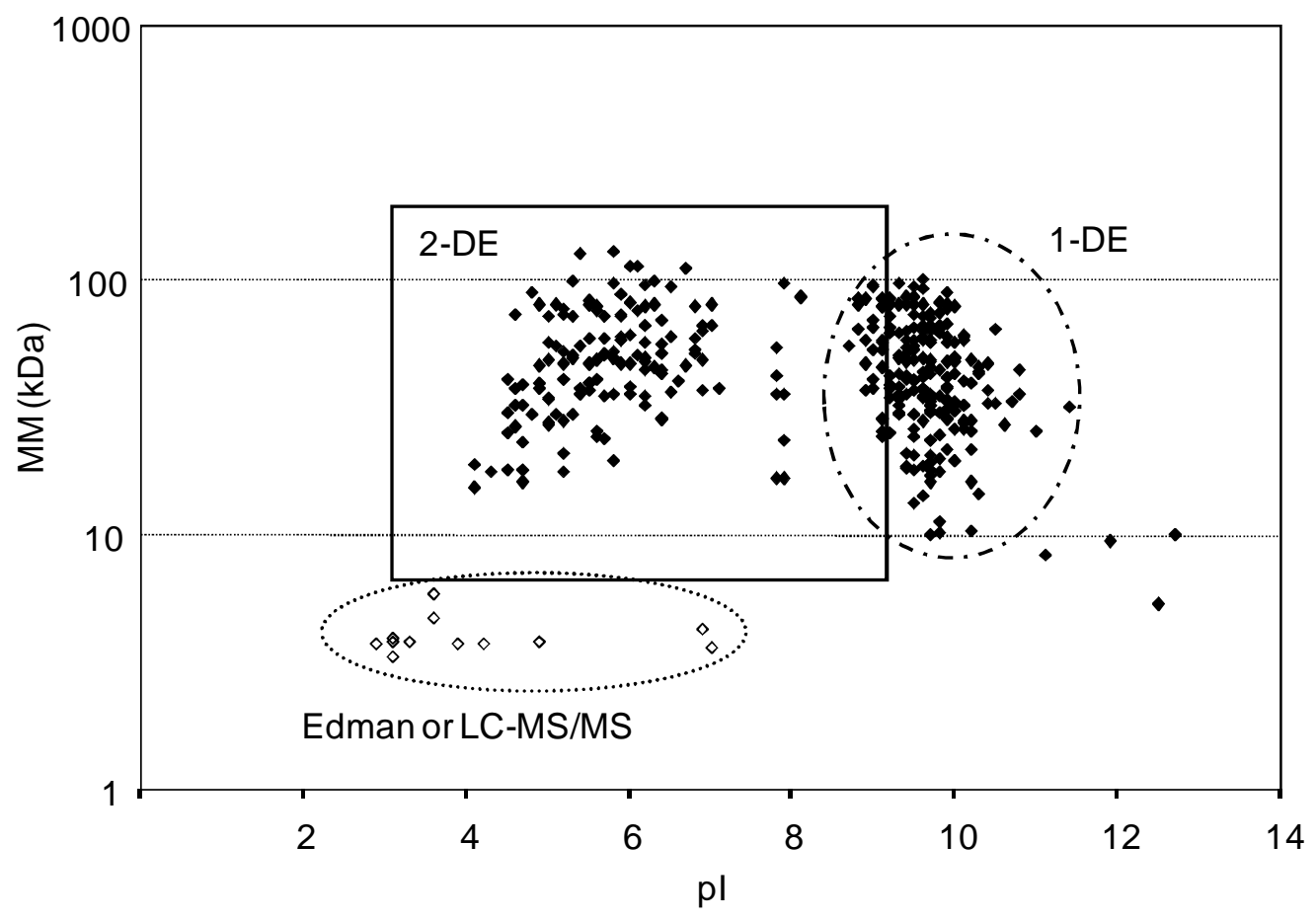

Figure 4. Virtual analysis of CWPs by 2-DE. $\mathrm{MM}(\mathrm{kDa})$ and $\mathrm{pI}$ of proteins identified in previous cell wall proteomic studies were calculated (http://www.iut-arles.up.univmrs.fr/w3bb/d abim/compo-p.html) and used to draw a virtual 2-DE gel where proteins are represented by diamonds. The rectangle shows the usual window of resolution of 2-DE gels. The oval broken line surrounds the majority of CWPs that have a basic $\mathrm{pI}$ and that have been analysed by $1-\mathrm{DE}$. The oval dotted line surrounds CWPs (open diamonds) that have small MM and that have been identified by Edman sequencing or LC-MS/MS.

\subsection{Evaluation of protocols}

At a large scale, the most efficient way to evaluate CWP extraction protocols for a proteomic study is to perform extensive bioinformatic analysis after identification of all the proteins by MS. The aim is to determine if the proteins identified contain a signal peptide, and no retention signals for other cell compartments. Several software packs should be used to ensure reliable prediction: PSORT predicts any sub-cellular location (http://psort.ims.u-tokyo.ac.jp/form.html); TargetP looks for the presence of signal peptides for protein secretion or transit peptides for mitochondrion or chloroplast targeting (http://www.cbs.dtu.dk/services/TargetP/). It is then possible to assess the quality of the extraction protocol by calculating the ratio of predicted secreted proteins to intracellular ones. However, such in silico approaches do not prove the extracellular location of proteins. In vivo approaches such as immunolocalization or localization by GFP (Green Fluorescent Protein) fusions should be performed. The lack of such experiments associated with cell wall proteomic studies constitutes a great weakness. 
Indeed, proteomic studies made on cell walls revealed leaderless proteins mixed with secreted proteins, many of which have well-known functions inside the cell. There have been many discussions about the possibility of finding non-canonical proteins in plant cell walls $[7,36]$. Are they bona fide secreted proteins or just contaminants? Recent studies have revealed that several proteins found in the extracellular matrix of animal cells can be secreted without a classical $\mathrm{N}$ terminal signal peptide [37]. Moreover, several cytosolic proteins called moonlighting proteins, have been experimentally shown to perform a second function outside the cell [38]. A nonclassical secretory pathway seems to work independently of the endoplasmic reticulum-Golgi network, since protein export is not troubled by monensin or brefeldin A, inhibitors of the classical secretory pathway [39]. A sequence-based method of prediction of non-classicaltriggered secretion for mammalian proteins, gram+, and gram- bacteria, has been developed (http://www.cbs.dtu.dk/services/SecretomeP-1.0). The assumption is that extracellular proteins share certain properties and features which can be related to protein function outside the cell, independently of the secretory process itself [40]. Extracellular proteins were used as positive input, while proteins known to be nuclear or cytoplasmic were used as negative input. Since the secretory mechanism of eukaryotes evolved early and seems to be common to animals and plants, we used SecretomeP set up to predict potential secretion of plant proteins. Fifty proteins found in several proteomic studies of Arabidopsis cell walls and devoid of predicted signal peptide were analyzed (Table 1). Only 14 are predicted as putative leaderless secreted proteins. It is interesting to note that many of the predicted non-classical secreted proteins are linked to lipid metabolism.

To validate the performance of this tool with plant proteins, the location of the potential secreted proteins listed in Table 1 should be proved on intact tissues and not on purified fractions. In addition, experiments should be performed to explore the possibilities of occurrence of moonlighting proteins performing new functions in cell walls. From the study of Bendtsen et al. on 21771 human proteins [40], only 46, excluding immunoglobins, were predicted to be secreted via the non-classical secretion pathway. This shows that this alternative pathway is very exceptional in contrast with the around 3600 proteins secreted through the $\mathrm{N}$-terminal one [40]. The very high number of known intracellular proteins found in many of the plant cell wall proteomic studies must alert us about the purity of the samples. However, we must be aware that MS approaches are considerably more sensitive than biochemical ones. For that reason, contaminants will always be detected in cell wall protein samples analyzed by MS tools, even as traces. The detection of these unexpected proteins in cell wall preparations is not sufficient per se to postulate that they are extracellular.

Table 1. Analysis of proteins without signal sequence with the SecretomeP software.

Proteins without signal peptide found in several proteomic analyses of Arabidopsis cell walls [10, $11,13-15,36]$ were analyzed using SecretomeP (http://www.cbs.dtu.dk/services/SecretomeP1.0). Scores higher than 0.600 were considered as significant as reported by Bendtsen et al. (2004) [40]. Among the 50 proteins analyzed, only 14 were predicted as potential candidates that may be exported via non-classical secretion. 


\begin{tabular}{|c|c|c|}
\hline $\begin{array}{c}\text { Gene } \\
\text { accession } \\
\text { number }\end{array}$ & Putative function & $\begin{array}{l}\text { Neural } \\
\text { Network- } \\
\text { score }\end{array}$ \\
\hline \multicolumn{3}{|c|}{ Predicted non-classical secretory proteins } \\
\hline At2g39050 & Homologous to lectin (ricin-type) & 0.903 \\
\hline At3g03060 & Homologous to ATPase (AAA family) & 0.843 \\
\hline At3g26060 & Peroxiredoxin Q & 0.837 \\
\hline At1g67880 & Glycosyl transferase family 17 & 0.836 \\
\hline At2g43710 & Homologous to fatty acid desaturase & 0.819 \\
\hline At1g43800 & Homologous to fatty acid desaturase & 0.813 \\
\hline At3g02630 & Homologous to fatty acid desaturase & 0.750 \\
\hline At1g72730 & Homologous to RNA helicase & 0.746 \\
\hline At1g15390 & Homologous to polypeptide deformylase & 0.729 \\
\hline At2g21170 & Homologous to triose phosphate isomerase & 0.655 \\
\hline At3g52960 & Homologous to peroxiredoxin & 0.648 \\
\hline At2g44350 & Citrate synthase 4 (ATCS) & 0.622 \\
\hline At4g36530 & Homologous to hydrolase (alpha/beta fold family protein) & 0.621 \\
\hline At3g16640 & Homologous to translationally controlled tumor protein (TCTP) & 0.608 \\
\hline \multicolumn{3}{|c|}{ Predicted intracellular proteins } \\
\hline At2g38870 & Homologous to proteinase inhibitor & 0.584 \\
\hline At5g20080 & $\begin{array}{l}\text { Unknown function (oxido-reductase NAD- and FAD-binding } \\
\text { domains) }\end{array}$ & 0.576 \\
\hline At1g72560 & Homologous to yeast exportin (PSD1) & 0.555 \\
\hline At2g17190 & Ubiquitin family & 0.552 \\
\hline At3g 15360 & Thioredoxin M type 4 (ATHM4) & 0.551 \\
\hline At2g36530 & Homologous to enolase & 0.547 \\
\hline At4g30690 & Homologous to translation initiation factor IF-3 & 0.536 \\
\hline At5g42980 & Thioredoxin H type 3 (ATTRX3) & 0.530 \\
\hline At4g17260 & Homologous to lactate/malate dehydrogenase & 0.525 \\
\hline At3g16400 & Homologous to jacalin (ATMLP-470) & 0.509 \\
\hline At5g49190 & Glycosyl transferase family 1 & 0.509 \\
\hline At1g03675 & Homologous to thioredoxin $\mathrm{M}$ & 0.499 \\
\hline At2g01520 & Homologous to pathogenesis-related protein Bet v I & 0.497 \\
\hline At3g15730 & Homologous to phospholipase D & 0.495 \\
\hline At3g14440 & Homologous to carotenoid oxygenase & 0.468 \\
\hline At3g04600 & Amino acid tRNA synthetase class I (W and $\mathrm{Y})$ & 0.458 \\
\hline At3g04120 & Glyceraldehyde-3-phosphate dehydrogenase C subunit (GAPC) & 0.456 \\
\hline At5g38420 & RuBisCO small subunit 2B (ATS2B) & 0.449 \\
\hline At1g56070 & Translation elongation factor (LOS1) & 0.411 \\
\hline
\end{tabular}




\begin{tabular}{|l|l|l|} 
At2g25630 & Glycosyl hydrolase family 1 & 0.399 \\
\hline At5g26710 & Amino acid tRNA synthetase class I (E and Q) & 0.397 \\
\hline At3g03060 & Homologous to ATPase (AAA family) & 0.391 \\
\hline At1g69290 & Unknown function (PPR repeats) & 0.386 \\
\hline At5g55990 & Homologous to calcineurin B & 0.365 \\
\hline At1g24360 & Homologous to dehydrogenase/reductase & 0.364 \\
\hline At3g30810 & Unknown function (DUF1633) & 0.346 \\
\hline At5g08740 & NAD(P)H dehydrogenase C1 & 0.338 \\
\hline At4g31180 & Amino acid tRNA synthetase class II (D, K and N) & 0.337 \\
\hline At1g30580 & Unknown function (GTPase domain, DUF933) & 0.324 \\
\hline At5g41550 & Unknown function (TIR domain, LRR domains) & 0.317 \\
\hline At4g37870 & Homologous to phospho enol pyruvate carboxykinase & 0.300 \\
\hline At3g16420 & Homologous to jacalin (PBP1) & 0.289 \\
\hline At4g22410 & Homologous to ubiquitin carboxyl-terminal hydrolase & 0.288 \\
\hline At3g58480 & Unknown function (calmodulin-binding domain) & 0.187 \\
\hline At5g46550 & Unknown function (bromodomain) & 0.183 \\
\hline & ARABIDOPSIS RESPONSE REGULATOR 1 (ARR1 (myb-like & \\
At3g16857 & DNA-binding domain) & 0.177 \\
\hline
\end{tabular}

\section{Structural features of CWPs}

A new challenge in cell wall proteomics is the fine description of CWP structures. Indeed, most of the time, systematic identification of CWPs through proteomic studies was performed regardless of post-translational modifications or interactions with other cell wall components. Structural characterization of some CWPs is now emerging, giving new insight into CWP structures.

Among PTMs of CWPs, hydroxylations of Pro and glycosylations are probably the most abundant since they occur during their transit through endoplasmic reticulum and Golgi apparatus. The two main types of plant glycosylations are $N$ - and $O$-glycosylations, depending on the residues carrying carbohydrates [41]. On the one hand, plant $N$-glycosylations take place on the consensus sequence Asn-Xaa-Thr/Ser, like in mammals, but display some structural specificities. On the other hand, $O$-glycosylations are encountered on Ser or Hyp, the latter being specific to plants.

Global approaches can be employed to describe glycoproteomes. First, glycoproteins must be detected by specific staining and/or isolated by appropriate chromatography for subsequent subproteome analysis by MS. Unlike mammals in which many glycoproteomes have been studied [23], plant glycoproteomes are still poorly described. However, some experimental data concerning glycosylations of CWPs are available. For instance, as many as 12 and 17 glycoforms of a subtilisin serine protease and a PGIP (polygalacturonase inhibitor protein), respectively, have been visualized by fluorescent staining with ProQ Emerald, specific for glycoproteins [27]. A shift in electrophoretic mobility following treatment with a peptide $N$-glycosidase enabled the presence of $N$-glycosylations on the COBRA protein to be demonstrated [42].

Recently, ConA chromatography was used to capture $N$-glycoproteins from mature Arabidopsis stems [22]. The cell wall sub-proteome obtained was rich in glycoside hydrolases 
(GH) and in multicopper oxidases. However, the $N$-glycopeptide structures were not described in this study. It is noteworthy to observe that expansins, known to be $N$-glycosylated [43], were missing from this glycoproteome. This illustrates the difficulties inherent to glycoproteomics, it is indeed challenging to identify all glycoproteins from an extract, enriched or not. Indeed, glycoproteins can escape the analysis at any level of a peptide mass mapping procedure: (i) electrophoresis separation, especially for heavily-glycosylated proteins that can be unable to migrate; (ii) detection, since glycoproteins can be insensitive to classical staining like CBB; (iii) tryptic digestion, because of possible steric hindrance of glycans near proteolytic sites; (iv) glycopeptide ionization, known to be less efficient than for unmodified peptides; (v) mass spectrum analysis, since glycopeptide masses are not listed in data banks. Considering these limits, studies focused on specific cell wall glycoproteins are more widespread than global approaches.

Peroxidases provide good examples of structurally-characterized cell wall $\mathrm{N}$-glycoproteins. Biochemical analysis of a soybean peroxidase (SBP) has revealed that it is a glycoprotein containing $18 \%$ carbohydrates $(\mathrm{w} / \mathrm{w})$ [44]. The oligosaccharides released with glycopeptidase A were analyzed by combining anion exchange chromatography and MALDI-TOF MS. They were shown to be of two types: the major oligosaccharides (up to $90 \%$ ) belong to the $(\mathrm{Xyl})_{\mathrm{x}} \mathrm{Man}_{\mathrm{m}}(\mathrm{Fuc})_{\mathrm{f}} \mathrm{GlcNAc}_{2}$ family $(\mathrm{m}=2-6 ; \mathrm{f}=0$ or $1 ; \mathrm{x}=0$ or 1$)$ while the remainder are oligosaccharides of the high-mannose type $\operatorname{Man}_{\mathrm{m}} \mathrm{GlcNAc}_{2}(\mathrm{~m}=5-9)$. In addition, SBP displays considerable heterogeneity in its pattern of $N$-glycosylation. MALDI-TOF-MS analyses of tryptic peptides indicated that all $\mathrm{N}$-glycosylation consensus sites can be glycosylated but not all sites are fully occupied [45]. Among the 7 putative Asn-Xaa-Thr consensus glycosylation sites for $\mathrm{N}$ linked glycans, only 3 are fully populated on Asn at positions 56, 130 and 144 . The other $4 \mathrm{~N}$ glycosylation consensus sequons occur in close pairs. The $\mathrm{Asn}^{185}-\mathrm{Asn}^{197}$ pair was found to be mainly $(85-90 \%)$ diglycosylated. In contrast, the $\mathrm{Asn}^{211}-\mathrm{Asn}^{216}$ pair occurs primarily as a monoglycosylated species, at the $\mathrm{Asn}^{211}$ site. This can be correlated to the fact that these two glycosylation sites are separated by only two amino acids. Indeed, since translation and glycosylation occur at the lumen of the endoplasmic reticulum, it is suggested that glycosylation at $\mathrm{Asn}^{211}$ will interfere with that of $\mathrm{Asn}^{216}$ by steric hindrance. In addition, glycan occupancy at $\mathrm{Asn}^{216}$ can be decreased because of the preceding Asp residue whose negative charge may reduce the oligosaccharyl transferase activity. Finally, analysis of the 3D-structure of SBP revealed that the amide of $\mathrm{Asn}^{216}$ is buried inside the structure, reducing its accessibility. In contrast, $\mathrm{Asn}^{185}$, $\mathrm{Asn}^{197}$ and $\mathrm{Asn}^{211}$ are either on convex surfaces or on a ridge. Unfortunately, glycans were not present on the crystal structure of SBP since a recombinant protein expressed in E. coli was used for crystallization experiments [46].

Pro hydroxylation and subsequent $O$-Hyp glycosylation are probably the most frequently described PTMs for CWPs. HRGPs, comprising extensins and AGPs, as well as H/PRPs, are major CWPs known to participate in plant extracellular matrix networks [47]. Modification of Pro residues occurs in the endoplasmic reticulum, concomitantly with protein translation. This can be followed by $O$-Hyp glycosylation by glycosyl transferases (GT) in the Golgi. However, Pro-4-hydroxylase does not hydroxylate all Pro residues in HRGPs or H/PRPs. Similarly, all Hyp residues are not glycosylated by GTs. It is now assumed that HRGP polypeptides themselves are the primary determinants of HRGP hydroxylation and glycosylation. Indeed, extensins, AGPs and H/PRPs can be distinguished by characteristic repetitive motifs in their primary sequence. An original approach using synthetic genes was carried out to produce a range of repetitive peptides 
carrying putative glycosylation motifs, which were subsequently characterized combining biochemical methods like circular dichroism, sugar and amino acid analyses or NMR [48], [35, 49]. These results, completed by studies on specific HRGPs isolated from plants [50-52] led to the proposal of the so-called Hyp- $O$-glycosylation code of CWPs and the concept of functional glycomodules, including Pro hydroxylation and glycosylation. Hyp- $O$-glycosylation occurs in two ways, namely arabinosylation and galactosylation. On the one hand, Hyp- $O$-arabinosylation is correlated with Hyp contiguity in sequences such as Xaa-Hyp $\mathrm{p}_{\mathrm{n}}$, Xaa being commonly Ser, Ala or $\mathrm{Thr}$, and $\mathrm{n} \geq 2$. Hyp- $O$-arabinosylation results in short, neutral, linear arabino-oligosaccharides

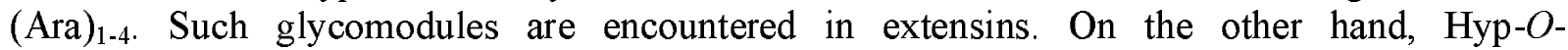
galactosylation is thought to occur on clustered non-contiguous Hyp residues (Xaa-Hyp) typically found in AGPs, Xaa being commonly Ser, Ala or Thr. These glycomodules direct the addition of large arabinogalactan polysaccharides, consisting in a $\beta$-1,3-galactan backbone, substituted at $\mathrm{C} 6$ or $\mathrm{C} 3$ by side chains containing galactose, arabinose, rhamnose, and glucuronic acid residues. Their length is diverse, ranging from 30 sugars/Hyp in gum arabic AGP, up to 150 sugars/Hyp in a radish leaf AGP [53]

Unlike HRGPs, few H/PRPs were characterized, from a structural and functional point of view. Repetitive blocks of Lys-Pro-Pro-Val-Tyr(Lys) are often found in H/PRPs. The presence of a Lys preceding Pro-Pro is thought to reduce glycosylation with arabino-oligosaccharides [50]. However, the limited number of structural studies performed on these proteins does not permit the extension of the concept of functional glycomodules established for other HRGPs. A nice structural study has been carried out on a basic H/PRPs cell wall glycoprotein extracted from styles of Nicotiana alata, a galactose-rich style glycoprotein (GaRSGP) [54]. SDS-PAGE analysis of the purified glycoprotein showed a smear ranging from 45 to $120 \mathrm{kDa}$, revealing a remarkable heterogeneity in its glycosylation pattern. After consecutive deglycosylation steps using anhydrous $\mathrm{HF}$ and $\mathrm{N}$-glycosidase, the protein was observed by electrophoresis as distinct bands at 31 and $29 \mathrm{kDa}$, respectively, indicating the presence of both $O$ - and $N$-linked glycans. GaRSGP was shown to consist of approximately $20-25 \%$ protein and $75-80 \%$ carbohydrates. GCMS analyses of trimethylsilyl-derivate carbohydrates and acetate alditols obtained from purified glycoprotein enabled galactose to be identified as the predominant monosaccharide with 83 mol\% of total carbohydrates and that it was shown that it can be terminal or linked through 1,3 or 1,6 or $1,3,6$ linkages. The remaining $17 \mathrm{~mol} \%$ carbohydrates consist notably of $4 \%$ mannose, encountered only in $\mathrm{N}$-glycans, suggesting that $\mathrm{O}$-glycosylation is the major glycosylated form. The amino acid composition of GaRSGP showed that Hyp is the most abundant residue ( 9 mol\%). However, biochemical evidence for $O$-glycosylation onto Hyp residues is still missing.

Other post-translationally modified proteins can be found in plant cell walls. GAPs are targeted to the plasma membrane. However, since the GPI-anchor can be cleaved by specific phospholipases, the proteins can exist in both soluble and membrane-associated forms. A large number of Arabidopsis GAPs has been identified or predicted by combining proteomic and bioinformatic analyses [12]. A sub-proteome has been obtained from callus cells using Triton X-114 phase partitioning and sensitivity to phosphatidylinositol-specific phospholipase C. The 30 proteins identified were shown to belong to 11 functional categories, such as AGPs, arabinogalactan (AG)-peptides, $\beta$-1,3-glucanases, Lipid Transfer Proteins (LTPs) or COBRA protein. PTMs of AG-peptides were more precisely characterized: they are processed in vivo for addition of a GPI-anchor, cleavage of signal peptide and GPI-anchor, Pro hydroxylation and 
subsequent glycosylation of Hyp residues [21]. Total AGPs were purified from Arabidopsis seedlings by $\beta$-Yariv precipitation and deglycosylated using anhydrous HF. MALDI-TOF MS and tandem MS/MS analyses of the deglycosylated extract enabled the identification of 10-17 amino acid-long AG-peptides without tryptic digestion. MS data clearly showed that all Pro residues can be hydroxylated, demonstrating that Pro hydroxylation is possible even in the GlyPro motif, previously described as unmodified. However, the efficiency of hydroxylation in GlyPro motif is thought to be reduced as compared with Ala-Pro. The structure of the polysaccharides carried by Arabidopsis AG-peptides has not been described so far but it is thought to be as complex as those described in other plants $[49,55,56]$.

Finally, a few reports suggest that CWPs may be phosphorylated. After separation by 2-DE and immunodetection using antibodies against phosphotyrosine residues, a lectin, a xyloglucanase and a chitinase were identified by MALDI-TOF MS in Arabidopsis [57]. A similar proteomic approach carried out on maize CWPs enabled the identification of three phosphotyrosine protein spots corresponding to peroxidases that were shown to be dephosphorylated in response to elicitor treatment [58]. However, as long as the presence of phosphate has not been demonstrated by a clear identification of phosphopeptides by MS experiments, the relevance of phosphorylated CWPs will remain uncertain. Indeed, even if an extracellular phosphorylation mechanism has been suggested [59], all protein kinases identified in Arabidopsis are predicted to be located in the cytosol [60]. The proteins claimed to be extracellular kinases in Arabidopsis are probably lectins, since no kinase domain can be found in these proteins by bioinformatic searches for functional motifs (http://www.ebi.ac.uk/InterProScan/).

Due to the particular environment of CWPs in cell walls, many of them interact with polysaccharides through specific domains. In addition, they may have protein/protein interaction domains. Some data are available to describe 3D-structures and provide a detailed description of such interactions. Expansins are assumed to promote turgor-driven extension of cell walls by altering interactions between cellulose microfibrils and hemicelluloses. The structure of a maize beta-expansin (EXPB1) has been recently obtained by X-ray crystallography [43]. It was shown to contain two domains that form a groove assumed to bind a glycan backbone of about ten sugar residues, as shown by in silico docking experiments. EXPB1 binds to different polysaccharides in vitro, with a higher affinity for xylans. It was assumed that EXPB1 binds to an arabinoxylan tethered to a cellulose microfibril causing its local release from the cellulose surface. Movement of EXPB1 along arabinoxylan-cellulose junctions could allow unzipping of hydrogen bonds between the polysaccharides, thus causing their displacement. The ability to promote cell wall extension has been recently described for a tobacco LTP [61]. It was shown that the conserved hydrophobic cavity of this LTP is required for in vitro activity. However, the hydrophobic partner of LTPs in cell walls is still unknown as well as is the precise mechanisms by which the charged LTPs interact with the cellulose/xyloglucan network to disrupt hydrogen bonds and allow cell wall extension. Another major polysaccharide of cell walls of dicots is pectin. Interactions of CWPs with pectin- $\mathrm{Ca}^{2+}$ has been described for a zucchini peroxidase [31] and a bean PGIP [62]. In both cases, the binding site consists of a cluster of four Arg /Lys residues that are positively charged at the slightly acidic cell wall $\mathrm{pH}$. It interacts in vitro with negatively charged polygalacturonic acids. Since the pectin- $\mathrm{Ca}^{2+}$ binding site of the peroxidase is not on the same side of the protein as its active site, binding to pectins leaves the protein fully active. On the contrary, the pectin- $\mathrm{Ca}^{2+}$ binding site of PGIP is located close to its interacting site with 
polygalacturonase (PG). It is assumed that PGIP is interacting with the PG substrate waiting for the enzyme to inhibit its degrading activity.

\section{Functional studies of CWPs}

Prediction of protein function or functional domains by bioinformatics is a very powerful tool to classify CWPs, to infer their biological or biochemical functions and to point out yet unknown proteins that can perform new functions. Results from comparisons of amino acid sequences (http://www.ncbi.nlm.nih.gov/BLAST/) and searches for functional domains (http://www.ebi.ac.uk/InterProScan/) were combined to propose a distribution of CWPs in functional classes [7]. The assumption was that proteins sharing functional domains have the same activity. It should be stressed that the function of only a small portion of the identified proteins has ever been experimentally demonstrated. Of course, this classification has to evolve to take into account new results obtained by other experimental approaches such as biochemistry or genetics. At present, such a classification can be proposed for 404 CWPs coming from several proteomic studies performed on Arabidopsis [9-22]. About $87 \%$ of these CWPs could be distributed in eight categories on the basis of predicted biochemical or biological functions. The remaining $13 \%$ consist of proteins of as yet unknown function. Some of them have domains of unknown functions (DUF) and/or are only present in plants. Proteins acting on polysaccharides are the most abundant $(26.0 \%)$. They are GH, GT, carbohydrate esterases, carbohydrate lyases and expansins. Three functional classes of CWPs are of equal importance: oxido-reductases (12.4\%) which include peroxidases, multicopper oxidases, berberine-bridge enzyme (S)reticulin:oxygen oxido-reductases, and germins; proteases (11.9\%) are of several types, i.e. subtilisins, Asp proteases, Cys proteases and Ser carboxypeptidases; proteins having interacting domains $(10.6 \%)$ include proteins interacting with proteins through leucine-rich repeat (LRR) domains, lectins interacting with sugars, enzyme inhibitors such as PGIPs, pectin methylesterases (PMEs) inhibitors and protease inhibitors. Proteins involved in signaling (7.4\%) are mainly AGPs and LRR-receptor protein kinases that have been identified through their extracellular LRR domains. Proteins related to lipid metabolism (5.4\%) mainly include proteins homologous to lipase/acylhydrolases, but also proteins homologous to glycerophosphodiesterases or LTPs. Only a few structural proteins $(1.8 \%)$ have as yet been identified in proteomic studies for the many reasons stressed above. Other proteins of various functions $(11.9 \%)$ were put together in a class called "miscellaneous" among which are proteins homologous to acid phosphatases and blue copper binding proteins. These proteins are awaiting additional experimental data to be more precisely classified. Next, several types of CWPs will be described to illustrate their diverse functions and to show their importance in plant development and in response to biotic or abiotic stresses.

A great proportion of the proteins identified by cell wall proteomic analyses act on carbohydrates. Plant GH are supposed to play various functions in cell wall metabolism, regulation of cell wall expansion and modification during development, defense, signaling and mobilization of storage reserves [63-66]. Since plant cell wall polysaccharides are very heterogeneous complex polymers, spectra of GH activities must be very diverse. Seventy-six out of $379 \mathrm{GHs}$ have already yet been identified by proteomics. A first group of GHs (GH families 1, $3,9,10,16,27,28,31,35,51$ according to http://afmb.cnrs-mrs.fr/CAZY/) comprises enzymes that could be involved in the reorganization of cell wall carbohydrates during growth and development [65]. For the majority of these enzymes, substrates are cellulose, xylan, 
xyloglucans, and pectins (homogalacturonan and rhamnogalacturonan I). These results suggest that xyloglucans and pectins might undergo important structural changes after their deposition in cell walls. Since some GH families have a broad substrate range, it was hypothesized that this allows effective modification of complex cell wall carbohydrates without requiring a high number of enzymes $[66,67]$. The second largest group of identified GHs could be involved in defense against pathogens. Chitinases (GH18, GH19) and $\beta-1,3$-glucanases (GH17) have been shown to possess antifungal activity [68]. A third group of GHs could be involved in glycoprotein PTMs. These enzymes are $\alpha$-L-arabinofuranosidases (GH3), chitinases (GH18, GH19), $\beta$-D-galactosidases (GH35), $\alpha$-D-mannosidases (GH38), and $\beta$-D-glucuronidases (GH79). The role of GHs in hydrolysis of carbohydrate moieties of AGPs has been particularly studied. A basic beta-galactosidase with high specificity toward $\beta-1,3-$ and $\beta-1,6$-galactosyl residues was shown to be involved in this mechanism [69]. Finally, 3 GHs identified by proteomics could be involved in the mobilization of storage reserves. In higher plants, sucrose can serve not only as an intermediate storage system alternative to starch, but also as a major carbohydrate translocator, osmoticum, regulator of gene expression and signal molecule. In plants, the cleavage of sucrose into glucose and fructose is performed by invertases (GH32) [70]. Cell wall invertases are thus considered as key enzymes in sucrose unloading, cell differentiation, and response to wounding or pathogens.

Several proteins known for their ability to inhibit cell wall modifying enzymes (CWMEIs) have been identified by proteomics in Arabidopsis. CWMEIs represent an expanding family of plant proteins which presumably act in defense by limiting the rate of degradation of the cell wall by microbial enzymes, thus reducing colonization of plant tissues by the pathogens that produce them. These include inhibitors of polygalacturonases (PGs), PMEs and xyloglucan endoglucanases.

PGIPs are widespread in the plant kingdom. They only inhibit fungal PGs; the degree of susceptibility of the PG depending on its mode of action [71]. Many plants possess more than one PGIP [72] with different abilities to inhibit pathogen PG [73]. The overexpression of pgip in plants efficiently contributes to reducing its susceptibility to a fungal pathogen [74]. PGIP belongs to the super family of LRR-proteins and this LRR-motif has been shown to be essential for its affinity and specificity for the PG ligand [75]. Interestingly, PGIPs also interact with polygalacturonic acid via a motif of four clustered Arg and Lys residues [62].

Pectin is demethylated to polygalacturonic acid by PMEs, thus favoring further cleavage of polygalacturonic chains by PGs. PMEs can be inhibited by a specific inhibitor. Unlike PGIPs, PME inhibitors exclusively inhibit plant PMEs [76]. PME inhibitors from Arabidopsis share strong structural homology with an inhibitor of tobacco invertase (Nt-CIF), but they recognize different target enzymes, as recently elucidated by crystallographic analysis [77, 78]. The overexpression of a PME inhibitor in Arabidopsis contributes to promote root length and makes the transformed plants less susceptible to a necrotrophic pathogen [79].

Another interesting family is that of inhibitors of hemicellulose-degrading enzymes from monocots such as endoxylanase inhibitors (XIP-, and TAXI-type) and from dicots, namely xyloglucan endoglucanase inhibiting proteins (XEGIPs). XIP and TAXI are specific inhibitors of microbial endoxylanases but do not inhibit plant endoxylanases [80]. GH10 and GH11 
endoxylanases are inhibited by XIP-I from wheat. The crystal structure of XIP-I complexed with xylanases revealed that the inhibitor possesses two independent enzyme-binding sites, an unusual feature allowing binding to two xylanases with different fold [81]. TAXI inhibits only GH11 endoglucanases [82]. XEGIP also inhibits a fungal GH12 xyloglucanase [83], but not endoxylanases of the GH10 and GH1 1 families [84]. Structural similarities indicate that wheat XIP-I is related to chitinases of the GH18 family, despite its lack of chitinolytic activity [85]. TAXI is related to a fungal Asp protease but does not exhibit any proteolytic activity [86]. Based on gene sequence homology and inhibitory activity, the tomato XEGIP presumably belongs to a superfamily including the carrot extracellular dermal glycoprotein (EDGP), the tobacco nectar NEC4 protein, and monocot TAXI-type inhibitors.

CWMEIs exhibit a high level of selectivity towards their protein targets. The analysis of the superfamily of glucanase inhibitors suggests that CWMEI can be structurally closely related to members of the glucanase family, raising the question their origin from a common protein ancestor. It is conceivable that gene sequence analysis data associated with elucidation of biochemical structure of inhibitors will rapidly allow the characterization of novel families of CWMEIs [87].

Several oxido-reductases such as peroxidases (23), multicopper oxidases-like (8), germin-like proteins (7), and homologs to berberine bridge enzymes (6) have been identified. Peroxidases are involved in many physiological and developmental processes that have been reviewed recently [88]. They can be involved in both cell elongation and in its arrest. In the latter case, they catalyze the formation of bridges across phenolic residues of lignins as well as between lignins and adjacent CWPs or polysaccharides. Multicopper oxidase-like proteins catalyse full, fourelectron reduction of dioxygen $\left(\mathrm{O}_{2}\right)$ to water $\left(\mathrm{H}_{2} \mathrm{O}\right)$ using a variety of substrates [89]. They belong to a large gene family of 19 members in Arabidopsis [90]. Only two members of the family have been studied, SKU5 (At4g12420) and SKS6 (AtIg41830). It was shown that SKU5 is involved in the control of root growth [91] and that SKS6 contributes to cotyledon vascular patterning during development [90].

Proteolytic enzymes are thought to be involved in maturation of enzymes, signaling, protein turnover, and defense against pathogens [92]. Previous studies localized protease activities in leaf intercellular fluids [93]. As mentioned above, results from proteomics revealed the existence of a great diversity of proteases. The subtilase family is the best represented (38\%) among the cell wall proteases identified by proteomics. It is particularly interesting because it is involved in the formation of peptide hormones and growth factors from precursor polypeptides in mammals [94]. As an example of peptide signaling in plants, the CLE (CLV3/ESR-related) genes encode small, basic, secreted proteins with a conserved stretch of 14 amino acids close to their $\mathrm{C}$-termini. These 14 amino acid-peptides are released by $\mathrm{N}$ - and $\mathrm{C}$-terminal processing by an as yet unknown protease and carry the biological activity $[95,96]$. In the same way, using MS techniques, the barley ARAI $\alpha$-L-arabinofuranosidase/ $\beta$ - $\mathrm{D}$-xylosidase was shown to be processed in vivo by removing about 130 amino acids from its $\mathrm{C}$-terminus [67]. On the other hand, the extracellular Ser protease SDD1 (STOMATAL DENSITY AND DISTRIBUTION 1) has been shown to be involved in the regulation of stomatal density and distribution in Arabidopsis [97]. ALE1 (ABNORMAL LEAF EPIDERMIS1) is also predicted to encode a Ser protease and is assumed to produce a peptide required for proper differentiation of epidermis [98]. CDR1 (CONSTITUTIVE DISEASE RESISTANT 1) encodes a putative Asp protease [99]. Over- 
expression of CDR1 causes dwarfism and resistance to virulent Pseudomonas syringae. It was shown that CDR1 generates a small mobile signal (3-10 kDa) sensitive to heating and to protease. However, the substrates of these three proteases are still unknown. Finally, proteases could be involved in processing and/or turnover of cell wall proteins since several plant cell wall proteomic analyses showed large discrepancies between observed and expected molecular masses of proteins $[13,18,25]$.

At the cell surface, some CWPs share functional domains with extracellular region of receptor-like kinases (RLKs) such as LRR, legume- and curculin-like lectin, LysM, Pro-rich, thaumatin, chitinase and DUF26 domains. Altogether, CWPs containing such regions represent a subset of 34 proteins among the 404 identified so far in proteomic studies. RLKs play fundamental roles in signal transduction and are involved in all aspects of plant biology, from early embryogenesis to disease resistance. The wide variety of structures of their extracellular regions makes them particularly suitable for sensing the cell environment [100]. Recent studies have shown that receptor homo- and hetero-oligomerization are essential events to regulate the signaling activity $[101,102]$. The versatility of receptor combinations at the cell surface may explain how signaling specificity is maintained at the cytoplasmic level. Since cell wall allows cell-to-cell communication [103], it is then tempting to add CWPs into the play. CWPs could enlarge the variety of combinations and, in turn, the plant cell signaling capacity.

Several examples of the comparison between the functional domains of CWPs and RLKs revealed common structural characteristics. (i) While the structure of legume-lectin domains of Arabidopsis CWPs and RLKs consist in a $\beta$-sandwich fold as for the canonical legume lectins, they lack an invariant Asp residue in the monosaccharide binding site [104, 105]. This residue is replaced by a His residue, except for two RLKs where it is conserved. It was then assumed that such lectin domains are unable to bind monosaccharides. However, there remains the possibility that the association of legume lectin domains of CWPs and RLKs restore a functional dimer with an active carbohydrate-binding site able to interact with simple or complex sugars. (ii) The LRRRLKs were distributed into subfamilies numbered from I to XIII [106]: this classification is based on the structural arrangement of LRR-domains and the organization of introns in the extracellular domains of RLKs. Using the same criteria, the LRR-CWPs were grouped into one class resembling the RLK-LRR subfamily X. Other LRR-CWPs which are annotated LRR-extensins and PGIPs did not fall into a defined LRR-RLK subfamily. (iii) Phylogenetic trees generated using the amino acid sequences corresponding to the DUF26 or curculin domains showed no specific clade for CWPs compared to RLK homologous regions (Fig. 5). In Fig. 5A, the At3g22060 DUF26-CWP and the At3g45860 DUF26-RLK showed a high degree of similarity and are clustered. The At5g43980 DUF26-CWP is grouped with the At5g40380 and At1g70530 DUF26-RLK. Fig. 5B shows that the curculin-RLK fall into two subfamilies, namely SD-1 and SD-2, as already described [106]. The At5g18470 curculin-CWP is clustered with the SD-1 RLK subfamily. Although grouped in a separate clade, the sequences of At1g78830, At1g78850 and At1g78860 curculin-CWPs show a high similarity to those of the SD-1 RLK subfamily. Altogether, these examples suggest the possibility that CWPs sharing domains with RLKs might participate in the assembly of hetero-oligomeric receptors and in signaling processes.

In addition to the crucial role of CWPs in growth and development, secreted proteins or peptides are involved in plant defense mechanisms in response to biotic or abiotic stresses. Families of antimicrobial peptides such as thionins, defensins, LTPs, hevein- and knottin-like 

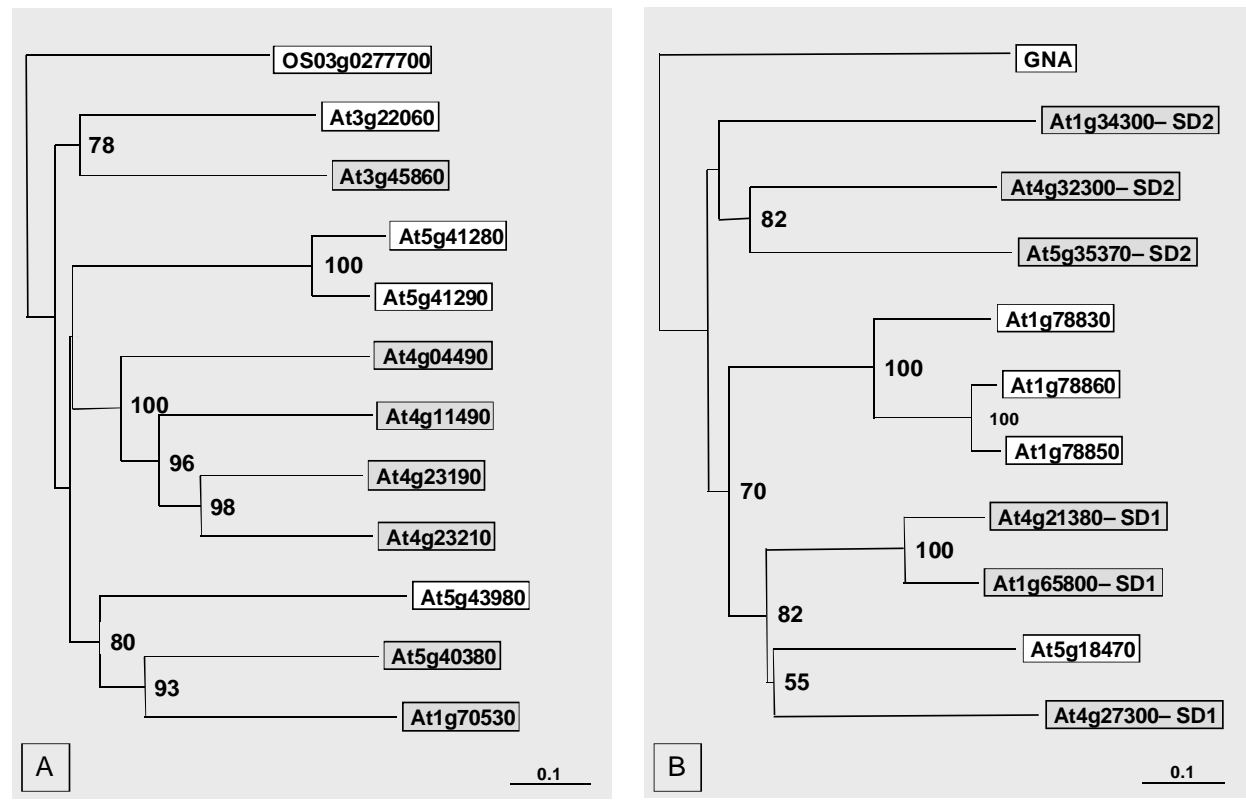

Figure 5. Neighbor-joining distance trees representing Arabidopsis thaliana DUF26 (A) and curculin (B) family members, based on the alignment (http://pbil.univlyon1.fr/software/seaview.html) of amino acid sequences of DUF26 and curculin domains as defined in Pfam database (http://pfam.jouy.inra.fr). The proteins considered are either CWP identified by proteomics (white boxes) or plasma membrane RLKs (grey boxes). The DUF26 tree was rooted with the DUF26 Oryza sativa secreted protein (accession number Os03g0277700). The curculin tree was rooted with GNA, an agglutinin secreted by Galanthus nivalis (accession number P30617). Bootstrap values were inferred from 1000 replicates (http://pbil.univlyon1.fr/software/phylowin.html). The numbers represent bootstrap support and branches with less than 50\% support are collapsed.

peptides have been described [107]. However, proteomic studies targeting these proteins have not been done. In a recent paper, changes in the Arabidopsis secretome were investigated in response to salicylic acid, a plant hormone that regulates defense signaling. Several proteins involved in pathogen response were identified, such as jacalin-related, LRR-containing proteins, esterase/lipase thioesterase, and the GLIP1 lipase. The characterization of GLIP1 confirmed that it is a secreted protein with antimicrobial activity, disrupting the fungal spores. Null mutants were markedly more susceptible to infections by the necrotrophic fungus Alternaria brassicicola [19]. Abiotic stresses have been shown to alter the protein composition of the apoplast both qualitatively and quantitatively. Changes in the tobacco leaf apoplast proteome in response to salt stress were analyzed. The abundance of 20 polypeptides changed in response to salt treatment, in particular two chitinases, an $\alpha$-galactosidase, and a germin-like proteins increased significantly, whereas two LTPs were de novo induced. On the contrary, the level of several peroxidases decreased as a consequence of salt stress [108]. Interestingly, two anther-specific proteins (putative LTPs) were down-regulated following low temperature treatment of rice anthers [109]. 


\section{Concluding remarks and future development}

Plant cell wall proteomics have brought a new vision of CWPs and cell wall functions. The diversity of cell wall modifying enzymes in all proteomes was probably not anticipated. This suggests that many changes occur at the level of polysaccharide networks not only during growth and development but also in mature organs. Major biological roles for proteolytic activities were only recently demonstrated in maturation of enzymes or production of extracellular peptidic signals. But there is still no information about CWP turnover which might be of critical importance in the regulation of extracellular functions. Up to now, protein/polysaccharide and protein/protein interactions have not been much studied to understand regulation of enzymatic activities and supra-molecular assembly of cell wall components. The existence of cell wall micro-domains is suggested by the specific binding to pectins in vitro of some CWPs devoid of hydrolytic activities towards polysaccharides. Finally, the finding that about $13 \%$ of CWPs are proteins of unknown function leaves open the possibility for new functions for cell walls.

Although our knowledge of cell wall proteomes and CWPs has greatly increased, many questions remain unanswered. They concern the exhaustive description of proteomes, the regulation of gene expression through PTM and protein degradation, the role of the cell wall in signaling via oligosaccharides, oligopeptides and possibly lipids, the precise biological function of proteins for which a biochemical function is predicted, and the role of proteins of yet unknown function.

Additional information on CWPs can be obtained using specific methods for extracting CWPs strongly bound to cell wall components. Efforts should be made to extract CWPs that are physically-linked to cell wall components, such as polysaccharides or lignins. Hydrolytic enzymes or chemicals could be used to degrade cell wall polysaccharides while maintaining protein integrity. Either new types of CWPs will be released or the same types as with salt solutions but linked in other ways to cell wall components. Similarly, the separation of CWPs prior to identification by mass spectrometry will, in all likelyhood be improved using liquid chromatography techniques instead of 2-DE $[110,111]$. Alternatively, MS analysis could also be done on peptide mixtures directly obtained from CWPs to skip the electrophoresis step that appears to be very limiting. Since quantitative data are still missing, accurate comparisons between samples can be pursued to perform differential proteomics [112, 113]. Many CWPs exhibit predicted interaction domains with other cell wall components, including polysaccharides, CWPs or plasma membrane proteins. Such interactions could be studied using the BIA (Biomolecular Interaction Analysis)-MS technology [114]. Since peptide signaling studies are becoming increasingly important, it would be interesting to develop specific approaches for plant cell wall peptidomics as has been done in animals [115], using the recently released secreted peptide database [116].

A comprehensive understanding of gene regulation requires all steps from gene transcription to protein degradation to be taken into account. Comparisons of transcriptomics and proteomics data show that the amount of an mRNA is not always strictly correlated with that of the translated protein. This correlation may depend on environmental conditions and/or on genes. For example, the quantification of soluble proteins of yeast at mid-log phase showed that for a given transcript level, protein levels were found to vary by more than 20 -fold, whereas for a given protein level, transcript levels were found to vary 30-fold [117]. However, upregulation of yeast genes in 
response to glucose or nitrogen limitation was found to be controlled at the transcription level or post-transcriptional level respectively [118]. In Arabidopsis and rice, changes observed in the soluble proteome in response to bacterial challenge were not strictly correlated to changes in transcript levels [119]. These results show that quantitative analysis of transcript levels is not sufficient to infer protein levels. Multilevel analysis must take into account protein degradation that is certainly essential considering the high number of proteases in cell walls.

The biological functions of most CWPs have not yet been experimentally studied. Proteomics gives information on the presence/absence of a protein in an organ or in response to environmental constraints as well as on PTMs possibly essential for its function. Bioinformatic predictions provide useful clues for the design of relevant experiments to understand its biochemical and biological functions. However, a full description of CWP biological functions will require complementary approaches including genetics, biochemistry, the study of patterns of expression and immunocytochemistry. Unexpected cell wall functions during plant development and adaptation to the environment will probably arise from these studies.

\section{Acknowledgements}

The authors thank Université Paul Sabatier (Toulouse III, France) and CNRS for financial support. They are grateful to Pr Christophe Roux (UMR 5546 CNRS/UPS for help in phylogenetic analyses and to Pr Peter Winterton (Université Paul Sabatier) for editing the English of the text.

\section{References}

1. Cassab G. I., Varner J. E., Cell wall proteins. Annu. Rev. Plant Physiol. Plant Mol. Biol. 1988, 39, $321-353$.

2. Carpita N. C., Gibeaut D. M., Structural models of primary cell walls in flowering plants: consistency of molecular structure with the physical properties of the walls during growth. Plant J. 1993, 3, 1-30.

3. Cosgrove D. J., Growth of the plant cell wall. Nat. Rev. Mol. Cell Biol. 2005, 6, 850-861.

4. Roberts K., How the cell wall acquired a cellular context. Plant Physiol. 2001, 125, 127-130.

5. Huckelhoven R., Cell wall-associated mechanisms of disease resistance and susceptibility. Annu. Rev. Phytopathol. 2007, in press.

6. Freshour G., Clay R. P., Fuller M. S., Albersheim P. et al., Developmental and tissue-specific structural alterations of the cell-wall polysaccharides of Arabidopsis thaliana roots. Plant Physiol. 1996, 110, 14131429 .

7. Jamet E., Canut H., Boudart G., Pont-Lezica R. F., Cell wall proteins: a new insight through proteomics. Trends Plant Sci. 2006, 11, 33-39.

8. Brady J. D., Sadler I. H., Fry S. C., Di-isodityrosine, a novel tetrametric derivative of tyrosine in plant cell wall proteins: a new potential cross-link. Biochem. J. 1996, 315, 323-327.

9. Basu U., Francis J. L., Whittal R. W., Stephens J. L. et al., Extracellular proteomes of Arabidopsis thaliana and Brassica napus roots: analysis and comparison by MUdPIT and LC-MS/MS. Plant Soil 2006, 286, 357376.

10. Bayer E. M., Bottrill A. R., Walshaw J., Vigouroux M. et al., Arabidopsis cell wall proteome defined using multidimensional protein identification technology. Proteomics 2006, 6, 301-311.

11. Borderies G., Jamet E., Lafitte C., Rossignol M. et al., Proteomics of loosely bound cell wall proteins of Arabidopsis thaliana cell suspension cultures: A critical analysis. Electrophoresis 2003, 24, 3421-3432.

12. Borner G. H., Lilley K. S., Stevens T. J., Dupree P., Identification of glycosylphosphatidylinositol-anchored proteins in Arabidopsis. A proteomic and genomic analysis. Plant Physiol. 2003, 132, 568-577.

13. Boudart G., Jamet E., Rossignol M., Lafitte C. et al., Cell wall proteins in apoplastic fluids of Arabidopsis thaliana rosettes: Identification by mass spectrometry and bioinformatics. Proteomics 2005, 5, 212-221. 
14. Charmont S., Jamet E., Pont-Lezica R., Canut H., Proteomic analysis of secreted proteins from Arabidopsis thaliana seedlings: improved recovery following removal of phenolic compounds. Phytochemistry 2005, 66.

15. Chivasa S., Ndimba B. K., Simon W. J., Robertson D. et al., Proteomic analysis of the Arabidopsis thaliana cell wall. Electrophoresis 2002, 23, 1754-1765.

16. Feiz L., Irshad M., Pont-Lezica R. F., Canut H. et al., Evaluation of cell wall preparations for proteomics: a new procedure for purifying cell walls from Arabidopsis hypocotyls. Plant Methods 2006, 2, 10 .

17. Haslam R. P., Downie A. L., Raventon M., Gallardo K. et al., The assessment of enriched apoplastic extracts using proteomic approaches. Ann. Appl. Biol. 2003, 143, 81-91.

18. Kwon H.-K., Yokoyama R., Nishitani K., A proteomic approach to apoplastic proteins involved in cell wall regeneration in protoplasts of Arabidopsis suspension-cultured cells. Plant Cell Physiol. 2005, 46, 843-857.

19. Oh I. S., Park A. R., Bae M. S., Kwon S. J. et al., Secretome analysis reveals an Arabidopsis lipase involved in defense against Alternaria brassicicola. Plant Cell 2005, 17, 2832-2847.

20. Robertson D., Mitchell G. P., Gilroy J. S., Gerrish C. et al., Differential extraction and protein sequencing reveals major differences in patterns of primary cell wall proteins from plants. J. Biol. Chem. 1997, 272, 15841-15848.

21. Schultz C. J., Ferguson K. L., Lahnstein J., Bacic A., Post-translational modifications of arabinogalactanpeptides of Arabidopsis thaliana. Endoplasmic reticulum and glycosylphosphatidylinositol-anchor signal cleavage sites and hydroxylation of proline. J. Biol. Chem. 2004, 279, 45503-45511.

22. Minic Z., Jamet E., Negroni L., Der Garabedian P. A. et al., A sub-proteome of Arabidopsis thaliana trapped on Concanavalin A is enriched in cell wall glycoside hydrolases. J. Exp. Bot. 2007, in press.

23. Harvey D. J., Proteomic analysis of glycosylation: structural determination of $N$ - and $O$-linked glycans by mass spectrometry. Expert Rev. Proteomics 2005, 2, 87-101.

24. Watson B. S., Lei Z., Dixon R. A., Sumner L. W., Proteomics of Medicago sativa cell walls. Phytochemistry 2004, 65, 1709-1720.

25. Zhu J., Chen S., Alvarez S., Asirvatham V. S. et al., Cell wall proteome in the maize primary root elongation zone. I. Extraction and identification of water-soluble and lightly ionically bound proteins. Plant Physiol. 2006, 140, 311-325.

26. Bhushan D., Pandey A., Chattopadhyay A., Choudhary M. K. et al., Extracellular matrix proteome of chickpea (Cicer arietinum L.) illustrates pathway abundance, novel protein functions and evolutionary perspect. J. Proteome Res. 2006, 5, 1711-1720.

27. Alvarez S., Goodger J. Q., Marsh E. L., Chen S. et al., Characterization of the maize xylem sap proteome. $J$. Proteome Res. 2006, 5, 963-972.

28. Alexandersson E., Saalbach G., Larsson C., Kjellbom P., Arabidopsis plasma membrane proteomics identifies components of transport, signal transduction and membrane trafficking. Plant Cell Physiol. 2004, $45,1543-1556$.

29. Lee S. J., Saravanan R. S., Damasceno C. M., Yamane H. et al., Digging deeper into the plant cell wall proteome. Plant Physiol. Biochem. 2004, 42, 979-988.

30. Voigt J., Extraction by lithium chloride of hydroxyproline-rich glycoproteins from intact cells of Chlamydomonas reinhardii. Planta 1985, 164, 379-389.

31. Carpin S., Crevecoeur M., De Meyer M., Simon P. et al., Identification of a Ca(2+)-pectate binding site on an apoplastic peroxidase. Plant Cell 2001, 13, 511-520.

32. Pitarch A., Sanchez M., Nombela C., Gil C., Sequential fractionation and two-dimensional gel analysis unravels the complexity of the dimorphic fungus Candida albicans cell wall proteome. Mol Cell Proteomics 2002, 1, 967-982.

33. Carter C., Pan P., Zouhar J., Avila E. L. et al., The vegetative vacuole proteome of Arabidopsis thaliana reveals predicted and unexpected proteins. Plant Cell 2004, 16, 3285-3303.

34. Mort A. J., Lamport D. T., Anhydrous hydrogen fluoride deglycosylates glycoproteins. Anal Biochem 1977, 82, 289-309.

35. Kieliszewski M. J., The latest hype on Hyp-O-glycosylation codes. Phytochemistry 2001, 57, $319-323$.

36. Slabas A. R., Ndimba B., Simon W. J., Chivasa S., Proteomic analysis of the Arabidopsis cell wall reveals unexpected proteins with new cellular locations. Biochem. Soc. Trans. 2004, 32, 524-528.

37. Rubartelli A., Sitia R., in: Kuchler K., Rubartelli A., Holland B. I. (Eds.), Unusual secretory pathways: from bacteria to man, Landes, Austin, Texas 1997, pp. 87-114.

38. Jeffery C. J., Mass spectrometry and the search for moonlighting proteins. Mass Spectrom. Rev. 2005, 24, $772-782$. 
39. Tanudji M., Hevi S., Chuck S. L., Improperly folded green fluorescent protein is secreted via a non-classical pathway. J. Cell Sci. 2002, 115, 3849-3857.

40. Bendtsen J. D., Jensen L. J., Blom N., Von Heijne G. et al., Feature-based prediction of non-classical and leaderless protein secretion. Protein Eng. Des. Sel. 2004, 17, 349-356.

41. Faye L., Boulaflous A., Benchabane M., Gomord V. et al., Protein modifications in the plant secretory pathway: current status and practical implications in molecular pharming. Vaccine 2005, 23, 1770-1778.

42. Roudier F., Fernandez A. G., Fujita M., Himmelspach R. et al., COBRA, an Arabidopsis extracellular glycosyl-phosphatidyl inositol-anchored protein, specifically controls highly anisotropic expansion through its involvement in cellulose microfibril orientation. Plant Cell 2005, 17, 1749-1763.

43. Yennawar N. H., Li L. C., Dudzinski D. M., Tabuchi A. et al., Crystal structure and activities of EXPB1 (Zea m 1), a beta-expansin and group-1 pollen allergen from maize. Proc. Natl. Acad. Sci. USA 2006, 103, 14664-14671.

44. Gray J. S., Yang B. Y., Hull S. R., Venzke D. P. et al., The glycans of soybean peroxidase. Glycobiology $1996,6,23-32$.

45. Gray J. S., Montgomery R., Asymmetric glycosylation of soybean seed coat peroxidase. Carbohydr. Res. 2006, 341, 198-209.

46. Henriksen A., Mirza O., Indiani C., Teilum K. et al., Structure of soybean seed coat peroxidase: a plant peroxidase with unusual stability and haem-apoprotein interactions. Protein Sci. 2001, 10, 108-115.

47. Showalter A. M., Structure and function of plant cell wall proteins. Plant Cell 1993, 5, 9-23.

48. Shpak E., Barbar E., Leykam J. F., Kieliszewski M. J., Contiguous hydroxyproline residues direct hydroxyproline arabinosylation in Nicotiana tabacum. J. Biol. Chem. 2001, 276, 11272-11278.

49. Tan L., Leykam J. F., Kieliszewski M. J., Glycosylation motifs that direct arabinogalactan addition to arabinogalactan-proteins. Plant Physiol. 2003, 132, 1362-1369.

50. Kieliszewski M. J., O'neill M., Leykam J., Orlando R., Tandem mass spectrometry and structural elucidation of glycopeptides from a hydroxyproline-rich plant cell wall glycoprotein indicate that contiguous hydroxyproline residues are the major sites of hydroxyproline O-arabinosylation. J. Biol. Chem. $1995,270,2541-2549$.

51. Kieliszewski M. J., Lamport D. T., Extensin: repetitive motifs, functional sites, post-translational codes, and phylogeny. Plant J. 1994, 5, 157-172.

52. Zhao Z. D., Tan L., Showalter A. M., Lamport D. T. et al., Tomato LeAGP-1 arabinogalactan-protein purified from transgenic tobacco corroborates the Hyp contiguity hypothesis. Plant J. 2002, 31, 431-444.

53. Nothnagel E. A., Proteoglycans and related components in plant cells. Int. Rev. Cytol. 1997, 174, $195-291$.

54. Sommer-Knudsen J., Clarke A. E., Bacic A., A galactose-rich, cell-wall glycoprotein from styles of Nicotiana alata. Plant J. 1996, 9, 71-83.

55. Fincher G. B., Sawyer W. H., Stone B. A., Chemical and physical properties of an arabinogalactan-peptide from wheat endosperm. Biochem J. 1974, 139, 535-545.

56. Tan L., Qiu F., Lamport D. T., Kieliszewski M. J., Structure of a hydroxyproline (Hyp)-arabinogalactan polysaccharide from repetitive Ala-Hyp expressed in transgenic Nicotiana tabacum. J. Biol. Chem. 2004, $279,13156-13165$.

57. Ndimba B. K., Chivasa S., Hamilton J. M., Simon W. J. et al., Proteomic analysis of changes in the extracellular matrix of Arabidopsis cell suspension cultures induced by fungal elicitors. Proteomics 2003, 3, 1047-1059.

58. Chivasa S., Simon W. J., Yu X. L., Yalpani N. et al., Pathogen elicitor-induced changes in the maize extracellular matrix proteome. Proteomics 2005, 5, 4894-4904.

59. Chivasa S., Ndimba B. K., Simon W. J., Lindsey K. et al., Extracellular ATP functions as an endogenous external metabolite regulating plant cell viability. Plant Cell 2005, 17, 3019-3034.

60. Rudrabhatla P., Reddy M. M., Rajasekharan R., Genome-wide analysis and experimentation of plant serine/ threonine/tyrosine-specific protein kinases. Plant Mol. Biol. 2006, 60, 293-319.

61. Nieuwland J., Feron R., Huisman B. A., Fasolino A. et al., Lipid transfer proteins enhance cell wall extension in tobacco. Plant Cell 2005, 17, 2009-2019.

62. Spadoni S., Zabotina O., Di Matteo A., Mikkelsen J. D. et al., Polygalacturonase-inhibiting protein interacts with pectin through a binding site formed by four clustered residues of arginine and lysine. Plant Physiol. $2006,141,557-564$.

63. Henrissat B., Coutinho P. M., Davies G. J., A census of carbohydrate-active enzymes in the genome of Arabidopsis thaliana. Plant Mol. Biol. 2001, 47, 55-72. 
64. Fry S. C., Primary cell wall metabolism: tracking the careers of wall polymers in living plant cells. New Phytol. 2004, 161, 641-675.

65. Minic Z., Jouanin L., Plant glycoside hydrolases involved in cell wall polysaccharide degradation. Plant Physiol. Biochem. 2006, 44, 435-449.

66. Minic Z., Do C. T., Rihouey C., Morin H. et al., Purification, functional characterization, cloning, and identification of mutants of a seed-specific arabinan hydrolase in Arabidopsis. J. Exp. Bot. 2006, 57, 23392351

67. Lee R. C., Hrmova M., Burton R. A., Lahnstein J. et al., Bifunctional family 3 glycoside hydrolases from barley with alpha -L-arabinofuranosidase and beta -D-xylosidase activity. Characterization, primary structures, and COOH-terminal processing. J. Biol. Chem. 2003, 278, 5377-5387.

68. Schlumbaum A., Mauch F., Vogeli U., Boller T., Plant chitinases are potent inhibitors of fungal growth. Nature 1986, 324, 365-367.

69. Kotake T., Dina S., Konishi T., Kaneko S. et al., Molecular cloning of a \{beta $\}$-galactosidase from radish that specifically hydrolyzes $\{$ beta $\}-(1->3)$ - and $\{$ beta $\}-(1->6)$-galactosyl residues of arabinogalactan protein. Plant Physiol. 2005, 138, 1563-1576.

70. Roitsch T., Gonzalez M. C., Function and regulation of plant invertases: sweet sensations. Trends Plant Sci. 2004, 9, 606-613.

71. Cook B. J., Clay R. P., Bergmann C. W., Albersheim P. et al., Fungal polygalacturonases exhibit different substrate degradation patterns and differ in their susceptibilities to polygalacturonase-inhibiting proteins. Mol. Plant Microbe Interact. 1999, 12, 703-711.

72. Favaron F., Gel detection of Allium porrum polygalacturonase-inhibiting protein reveals a high number of isoforms. Physiol. Mol. Plant Pathol. 2001, 58, 239-245.

73. Desiderio A., Aracri B., Leckie F., Mattei B. et al., Polygalacturonase-inhibiting proteins (PGIPs) with different specificities are expressed in Phaseolus vulgaris. Mol. Plant Microbe Interact. 1997, 10, 852-860.

74. Manfredini C., Sicilia F., Ferrari S., Pontiggia D. et al., Polygalacturonase-inhibiting protein 2 of Phaseolus vulgaris inhibits BcPG1, a polygalacturonase of Botrytis cinerea important for pathogenicity, and protects transgenic plants from infection. Physiol. Mol. Plant Pathol. 2005, 67, 108-115.

75. Leckie F., Mattei B., Capodicasa C., Hemmings A. et al., The specificity of polygalacturonase-inhibiting protein (PGIP): a single amino acid substitution in the solvent-exposed beta-strand/beta-turn region of the leucine-rich repeats (LRRs) confers a new recognition capability. EMBOJ. 1999, 18, 2352-2363.

76. Bellincampi D., Camardella L., Delcour J. A., Desseaux V. et al., Potential physiological role of plant glycosidase inhibitors. Biochim. Biophys. Acta 2004, 1696, 265-274.

77. Hothorn M., Wolf S., Aloy P., Greiner S. et al., Structural insights into the target specificity of plant invertase and pectin methylesterase inhibitory proteins. Plant Cell 2004, 16, 3437-3447.

78. Hothorn M., D'angelo I., Marquez J. A., Greiner S. et al., The invertase inhibitor Nt-CIF from tobacco: a highly thermostable four-helix bundle with an unusual N-terminal extension. J. Mol. Biol. 2004, 335, 987995.

79. Lionetti V., Raiola A., Camardella L., Giovane A. et al., Overexpression of pectin methylesterase inhibitors in Arabidopsis restricts fungal infection by Botrytis cinerea. Plant Physiol. 2007, 143, 1871-1880.

80. Flatman R., Mclauchlan W. R., Juge N., Furniss C. et al., Interactions defining the specificity between fungal xylanases and the xylanase-inhibiting protein XIP-I from wheat. Biochem. J. 2002, 365, 773-781.

81. Payan F., Leone P., Porciero S., Furniss C. et al., The dual nature of the wheat xylanase protein inhibitor XIP-I: structural basis for the inhibition of family 10 and family 11 xylanases. J. Biol. Chem. 2004, 279, 36029-36037.

82. Gebruers K., Debyser W., Goesaert H., Proost P. et al., Triticum aestivum L. endoxylanase inhibitor (TAXI) consists of two inhibitors, TAXI I and TAXI II, with different specificities. Biochem. J. 2001, 353, 239-244.

83. Qin Q., Bergmann C. W., Rose J. K., Saladie M. et al., Characterization of a tomato protein that inhibits a xyloglucan-specific endoglucanase. Plant J. 2003, 34, 327-338.

84. Naqvi S. M., Harper A., Carter C., Ren G. et al., Nectarin IV, a potent endoglucanase inhibitor secreted into the nectar of ornamental tobacco plants. Isolation, cloning, and characterization. Plant Physiol. 2005, 139, 1389-1400.

85. Payan F., Flatman R., Porciero S., Williamson G. et al., Structural analysis of xylanase inhibitor protein I (XIP-I), a proteinaceous xylanase inhibitor from wheat (Triticum aestivum, var. Soisson). Biochem. J. 2003, 372, 399-405.

86. Sansen S., De Ranter C. J., Gebruers K., Brijs K. et al., Structural basis for inhibition of Aspergillus niger xylanase by Triticum aestivum xylanase inhibitor-I. J. Biol. Chem. 2004, 278, 36022-36028. 
87. Durand A., Hughes R., Roussel A., Flatman R. et al., Emergence of a subfamily of xylanase inhibitors within glycoside hydrolase family 18. FEBS J. 2005, 272, 1745-1755.

88. Passardi F., Penel C., Dunand C., Performing the paradoxical: how plant peroxidases modify the cell wall. Trends Plant Sci. 2004, 9, 532-540.

89. Solomon E. I., Machonkin T. E., Sundaram U. M., in: Messerschmidt A. (Eds.), Multicopper oxidases, World Scientific Publishing Co., Singapore 1997, pp. 103-207.

90. Jacobs J., Roe J. L., SKS6, a multicopper oxidase-like gene, participates in cotyledon vascular patterning during Arabidopsis thaliana development. Planta 2005, 222, 652-666.

91. Sendbrook J. C., Carroll K. L., Hung K. F., Masson P. H. et al., The Arabidopsis SKU5 gene encodes an extracellular glycosyl phosphatidylinositol-anchored glycoprotein involved in directional root growth. Plant Cell 2002, 14, 1635-1648.

92. Schaller A., A cut above the rest: the regulatory function of plant proteases. Planta 2004, 220, 183-197.

93. Huangpu J., Graham J. S., Purification and developmental analysis of an extracellular proteinase from young leaves of soybean. Plant Physiol. 1995, 108, 969-974.

94. Rautengarten C., Steinhauser D., Büssis D., Stinzi A. et al., Inferring hypotheses on functional relationships of genes: analysis of the Arabidopsis thaliana subtilase gene family. PLoS Comput. Biol. 2005, 1, e40.

95. Ito Y., Nakanomyo I., Motose H., Iwamoto K. et al., Dodeca-CLE peptides as suppressors of plant stem differentiation. Science 2006, 313, 8842-8845.

96. Kondo T., Sawa S., Kinoshita A., Mizuno S. et al., A plant peptide encoded by CLV3 identified by in situ MALDI-TOF MS analysis. Science 2006, 313, 845-848.

97. Berger D., Altmann T., A subtilisin-like serine protease involved in the regulation of stomatal density and distribution in Arabidopsis thaliana. Genes Dev. 2000, 14, 1119-1131.

98. Tanaka H., Onouchi H., Kondo M., Hara-Nishimura I. et al., A subtilisin-like serine protease is required for epidermal surface formation in Arabidopsis embryos and juvenile plants. Development 2001, 128, 46814689.

99. Xia Y., Suzuki H., Borevitz J., Blount J. et al., An extracellular aspartic protease functions in Arabidopsis disease resistance signaling. EMBO J. 2004, 23, 980-988.

100. Johnson K. L., Ingram G. C., Sending the right signals: regulating receptor kinase activity. Curr. Opin. Plant Biol. 2005, 8, 648-656.

101. Li J., Wen J., Lease K. A., Doke J. T. et al., BAK1, an Arabidopsis LRR receptor-like protein kinase, interacts with BRI1 and modulates brassinosteroid signaling. Cell 2002, 110, 213-222.

102. Wang X., Li X., Meisenhelder J., Hunter T. et al., Autoregulation and homodimerization are involved in the activation of the plant steroid receptor BRI1. Dev. Cell 2005, 8, 855-865.

103. Brownlee C., Role of the extracellular matrix in cell-cell signalling: paracrine paradigms. Curr. Opin. Cell Biol. 2002, 5, 396-401.

104. Gouget A., Senchou V., Govers F., Sanson A. et al., Lectin receptor kinases participate in protein-protein interactions to mediate plasma membrane-cell wall adhesions in Arabidopsis. Plant Physiol. 2006, 140, 81 90.

105. Barre A., Hervé C., Lescure B., Rougé P., Lectin receptor kinases in plants. Crit. Rev. Plant Sci. 2002, 21, 379-399.

106. Shiu S. H., Bleecker A. B., Receptor-like kinases from Arabidopsis form a monophyletic gene family related to animal receptor kinases. Proc. Natl. Acad. Sci. USA 2001, 98, 10763-10768.

107. Garcia-Olmedo F., Molina A., Alamillo J. M., Rodriguez-Valenzuela P., Plant defense peptides. Peptide Sci. 1998, 47, 479-491.

108. Dani V., Simon W. J., Duranti M., Croy R. R., Changes in the tobacco leaf apoplast proteome in response to salt stress. Proteomics 2005, 5, 737-745.

109. Imin N., Kerim T., Weinman J. J., Rolfe B. G., Low temperature treatment at the young microspore stage induces protein changes in rice anthers. Mol. Cell. Proteomics 2006, 5, 274-292.

110. Stasyk T., Huber L. A., Zooming in: fractionation strategies in proteomics. Proteomics 2004, 4, 3704-3716.

111. Lescuyer P., Hochstrasser D. F., Sanchez J. C., Comprehensive proteome analysis by chromatographic protein prefractionation. Electrophoresis 2004, 25, 1125-1135.

112. Hamdan M., Righetti P. G., Modern strategies for protein quantification in proteome analysis: advantages and limitations. Mass Spectrom. Rev. 2002, 21, 287-302.

113. Moritz B., Meyer H. E., Approaches for the quantification of protein concentration ratios. Proteomics 2003, $3,2208-2220$. 
114. Lopez F., Pichereaux C., Burlet-Schiltz O., Pradayrol L. et al., Improved sensitivity of biomolecular interaction analysis mass spectrometry for the identification of interacting molecules. Proteomics 2003, 3 , 402-412.

115. Schulz-Knappe P., Schrader M., Zucht H. D., The peptidomics concept. Comb. Chem. High Throughput Screen. 2005, 8, 697-704.

116. Lease K. A., Walker J. C., The Arabidopsis unannotated secreted peptide database, a resource for plant peptidomics. Plant Physiol. 2006, 142, 831-838.

117. Gygi S. P., Rochon Y., Franza B. R., Aebersold R., Correlation between protein and mRNA abundance in yeast. Mol. Cell. Biol. 1999, 19, 1720-1730.

118. Kolkman A., Daran-Lapujade P., Fullaondo A., Olsthoorn M. M. et al., Proteome analysis of yeast response to various nutrient limitations. Mol. Syst. Biol. 2006, 2, 2006.0026.

119. Jones A. M., Thomas V., Truman B., Lilley K. et al., Specific changes in the Arabidopsis proteome in response to bacterial challenge: differentiating basal and R-gene mediated resistance. Phytochemistry 2004, $65,1805-1816$. 